\title{
Analysis of Social Media Influence on New Generation Rural Migrant Workers' Continuing Vocational Learning
}

\author{
Bin $\mathrm{Li}$ \\ Communication Studies Department \\ Jilin Agricultural University \\ Changchun, China
}

\author{
$\mathrm{Su} \mathrm{Huo}$ \\ Jilin University Library \\ Jilin University \\ Changchun, China
}

\begin{abstract}
The purpose of this study is to take sample survey of rural migrant workers in Northeast China, and analyze the influence factors of continuing vocational learning through selfdesigned questionnaire scales. Because social media has become the most important media in new generation migrant workers' daily life and develops stronger depending effect, in social media building communication context, migrant workers cannot only receive information or be entertained, but also build the interpersonal relationship, even acquire a lot of vocational experience and skills from their workmates or public platform. The results of regression factors predict procedure show that gender, working place, personal relationship keeping function, public platform of social media all predict the positive vocational learning motivation, and education level, media literacy, public information supply all predict the positive vocational learning behavior. So we can conclude that factors such as media literacy, social media information resource supply, migrant workers personal difference and vocational developing motivation will influence the migrant workers effective studying strategy.
\end{abstract}

Keywords—new generation rural migrant worker; social media; influence; continuing vocational learning; social learning theory

\section{INTRODUCTION}

Urban area, which is made up of relatively dense population accumulation area in a long time, has more modernization development opportunities and more convenient public facilities service. And the people migration and fusion has become the symbol mark of social modernity. So urban area will attract the rural floating population into, most of them are migrant workers who have to change their life style. In order to live a better life in urban area, these rural migrant workers have to give up rural agriculture skills, and attempt to conduct some life style transformation, to be hired in nonagricultural industry for survival and living resources. The Institute of Sociology in the Chinese Academy of Social Sciences has published some research results in the Social Development Blue Book (2012), which points out that China's urban population has been exceeded more $50 \%$ than the rural population for the first time and the proportion of rural migrant workers who engaged in non-agricultural or part-time farming have increased, it has been the embodiment of the urbanization development level. Meanwhile, it brought about some

The paper has sponsored by Jilin Province Educational Department Vocational Education Project(2015CZY328)and Jilin Province Science Department Project(Research of Platform Building of Jilin Migrant Workers return to start up business.2017). important problems which influence social stability and development in urban area, and gradually made rural area lose so much young labor force. Because of the low level of rural migrant workers' education, and lack of competitiveness in labor skills, in order to meet urban social structural employment demand, rural migrant workers often choose into low entry threshold and low technical level profession field. Young generation migrant workers always have been in the pursuit of the same life style as urban peer, but they have a weak acquisition and disposal ability of social capital with little relationship, so they are often marginalized by the city life. Migrant workers are lack of the same rights and interests which have been supported by government as urban residents, also lack of personal value and social attribution of "urbanization". All of these problems need reasonable right expression platform to provide fairly opportunity.

New generation migrant rural workers are defined as the generation in China who were born in the 1980s and 1990s even later moved from rural areas to live and work in the cities. In the view of the current situation, the young rural migrant workers who are eager to integrate into urban life are still marginalized in the urban society. Although they live in the urban area, new generation migrant workers still have gaps in thoughts and feelings compared with local people. Vocation seeking and adaptation, that is becoming the common basement in the urban life for new generation migrant workers without else society capital. In order to integrate into new life circumstance, the youth generation attempt to seek comprehensive ways to solve realistic questions. "On the gratifications for individual seek, and on the role of the mass media play in meeting people needs, it seems obvious that people do use media in varying ways" [1]. Young rural migrant workers have become increasingly dependent on digital media, which is used for meeting needs to obtain information and communicate with the outside world on a daily basis, to get the same vacation information and personal identity in workplace. According to statistics of the 33rd Report of Internet Development from CNNIC, by December 2013, rural users have reached 0.177 billion, accounting for $28.6 \%$ of the total Internet users. The increasing scale of rural Internet users has made it possible to enhance new media literacy of young rural migrant workers. What's more, the original digital gap will be narrowed after they come to the urban area and live in the new communications context constructed by the mass media. 
The new generation migrant workers are wandering between urban and rural, they hope to have different urban life style compared with their parents, which can have no longer constrained expression of policy, and have real expectations to change their destiny through personal strivings. From passive spreading by media discourse endorsements, and insight into the public opinion, the new generation rural migrant workers will get more opportunity and rights to change their media imagination, gradually realize and identify the symbolic meaning of medium express. And on the basis of hierarchical system, rural migrant workers establish different media use and dependence. Based on the new generation peasant workers' education level and growth promotion of media literacy, the new generation migrant workers and the mass media have cultivated interactive relation, on the discourse expression subject consciousness and ability, to bridge the migrant workers in urban and rural cultural fracture effect.

\section{LITERATURE REVIEW}

Age differences largely determine new generation migrant workers' advantaged media relationship compared with their parents, especially in using new digital media. Huang [2] pointed that mass media played important roles in information provision, speech rights and image formation which new generation migrant rural workers are in need of. Jiang[3] suggested that young rural migrant workers' attempt to change the status quo may be dissimilated into psychological imbalance which may negatively influences social stability. He proposed some strategies for new generation rural migrant workers' public opinion guidance and political participation. Particularly, young rural migrant workers have developed an increasingly intimate relationship with interactive media, which plays an essential role in their daily life. Zhou[4] used the stratified questionnaire to survey in Shanghai about the new media use and assessment of young rural migrant workers, it found that interpersonal communication, leisure and recreation have become the main functions of new generation migrant workers' media use. Mass media has facilitated the integration of new generation migrant rural workers into the urban life through new communication model[5].

However, the intergeneration layering research concerning the media use of migrant workers in China has not been given adequate attention, with the majority of research focusing on migrant workers as a whole. The internal differentiation of rural migrant workers should be the basis of research for communication studies. What's more, previous studies on media use tend to examine media popularizing rate and media assessment, and there is a lack of research taking young rural migrant workers as audience subject. Many observers believe that the mass media generate a considerable amount of "social teaching" [6]. But there is a lack of research analyzing the individual and social factors influencing young rural migrant workers' career adaptation. In fact, social media constructed a communication environment which can promote migrant workers to enhance career capacity, personal relationship, vocational technique, even cultivate career plan. It is different with some researchers who thought social media only brought with entertainment and virtual world, to cause them to lose their own self-awareness.
This empirical research is based on the theory of Social Learning Theory. It takes the young rural migrant workers as subject, to examine the influence of social media on their leaning cognitive motivation, behavior in the interactional environment. Such as social media like We Chat and microblog, it builds the integrated communication environment which does not need more real local urban experience and formal schooling education difference. So migrant workers' learning behavior will depend on their vocational personal attitude or need interactive adaptation in the environment.

Difference from the research methods of the past research literature: First, research view and method have changed, that is, from the case of qualitative research interview and observation method, to make a transition to the empirical investigation way. The case study focused on local description analysis, it failed to have the defects of regularity and characteristics of rural migrant workers in media research. Even though these empirical studies about new generation migrant workers limited in some regions, which input a large number of migrant workers, such as the Yangtze river delta, Beijing, Shanghai, the other field distributed in the main output of Sichuan, Henan and relevant provinces. The northeast region of the sample is rarely, the reason is relevant with the regional differences of rural migrant workers in media perspective research significance. At the same time, there are little literature to guide the new generation migrant workers into the urban area, based on media support and mass media service strategy and platform construction. Second, the domestic media's perspective of intergenerational layered on the problems of rural migrant workers have not been fully appreciated, the new migrant workers initiative attitude and behavior in media communication activities still have been ignored, they have not been taken as initiative participants. The disadvantage of this kind of research is very apparent, new generation migrant workers` education level, income level and media terminal has formed different media dependency compared with their parents group. New generation migrant workers groups within the migrant workers should be differentiated from the perspective of media using habit and daily dependent.

\section{METHOD}

\section{A. Participants}

The investigated samples of migrant workers have been controlled in the age range of 16-30 years old, and the demographic variables are divided into gender, educational level, income level, profession classification and working place to discriminate the social media contact and media using habit in order to meet their vocational learning and vocational adaptation in that media interactive communication context.

The study was implemented from March to May, 2016 through migrant workers working place research and online research, which is based on interviews with 20 migrant workers and panel research results. Self-designed questionnaire was used to investigate 300 new generation rural migrant workers. Valid samples are 297( $\mathrm{N}=297)$. At the 95\% Confidence coefficient condition, maximum error has been no more than $\pm 3.6 \%$. 


\section{B. Procedure}

Social media using and vocational learning influence selfcompiled questionnaire includes 28 items. It includes 4 dimensions: social media using contact involves 7 items; personal character difference involves 7 items, media referenced vocational resource supply involves 7 items, vocational developing motivation involves 7 items. The questionnaire used Likert 5-point scale assessment (from "very unimportant" to "very important"), it indicates that the more score of the scale form, the stronger the influence level. Questionnaire Confirmatory factor analysis: $\mathrm{CFI}=0.92, \mathrm{NFI}=0.94, \mathrm{TLI}=0.95, \mathrm{RMSEA}=0.08$, which indicates that the questionnaire has good structural validity. The whole questionnaire coefficient of $\alpha$ is 0.93 respectively.

\section{RESULTS AND DisCUSSION}

\section{A. Regression Predict Vocational Learning Motivation Influenced Factors}

Using demographic variable and social media using contact (personal relationship keeping function and public media platform) as independent variables and vocational learning motivation as dependent variable, the Compel-Enter method was employed to make linear regression analysis. The results are shown in Table I.

TABLE I. REGRESSION COEFFICIENTS

\begin{tabular}{|c|c|c|c|c|c|}
\hline \multirow[t]{2}{*}{ Model } & \multicolumn{2}{|c|}{$\begin{array}{c}\text { Unstandardized } \\
\text { Coefficients }\end{array}$} & \multirow{2}{*}{$\begin{array}{c}\begin{array}{r}\text { Standardized } \\
\text { Coefficients }\end{array} \\
\text { Beta }\end{array}$} & \multirow[b]{2}{*}{$\mathrm{t}$} & \multirow[b]{2}{*}{ Sig. } \\
\hline & B & Std. Error & & & \\
\hline (Constant) & .558 & .642 & & 3.190 & .003 \\
\hline Gender & .201 & .196 & .301 & 2.436 & .128 \\
\hline Education Level & .297 & .077 & .249 & 2.596 & .002 \\
\hline $\begin{array}{l}\text { Income per } \\
\text { month }\end{array}$ & -.043 & .078 & .089 & -.792 & 501 \\
\hline Working place & -.048 & .046 & 099 & .956 & 401 \\
\hline Profession & -0.26 & .077 & 048 & .425 & .757 \\
\hline $\begin{array}{l}\text { Personal } \\
\text { relationship } \\
\text { function }\end{array}$ & 195 & .088 & .842 & 3.286 & .025 \\
\hline Public platform & .229 & .059 & .521 & 3.201 & .000 \\
\hline
\end{tabular}

Demographic variable and social media using contact variable can predict vocational learning motivation dimension significantly $(\mathrm{F}=3.190, \mathrm{p}=0.003<0.05)$. Among the variables, gender, working place, personal relationship keeping function, and public platform of social media all predict the positive vocational learning motivation.
Female migrant workers vocational learning motivation have been demonstrated higher than male, it is relevant to jobhunting opportunity, because male migrant workers have more advantaged resource than female in job-hunting. The pressure of job-hunting promoted female migrant workers to make use of daily social media to learn vacation information and knowledge. Meanwhile, vocational learning demand manifest different in all kinds of working places, it depends on vocational learning atmosphere, leadership influence, learning support.

Through social media personal relationship keeping function, migrant workers can share information and criticism with friends, workmate and relevant vocational people, gradually personal interaction help them to cultivate career value and acquire life reality changing power. Although Public platform of social media provided information agenda which have focused on urban audience, rural migrant workers can also increase vocation learning opportunity, course and technique through the urban public mass media service, to acquire almost same vocational developing standard, and change them to be urban people.

\section{B. Regression Predict Vocational Learning Behavior Influence Factors}

Using demographic variable, media literacy and public information supply as independent variables and vocational learning behavior as dependent variable, the Compel-Enter method was adopted to make linear regression analysis; the results can be seen in Table II.

\section{TABLE II. REGRESSION COEFFICIENTS}

\begin{tabular}{|c|c|c|c|c|c|}
\hline \multirow[t]{2}{*}{ Model } & \multicolumn{2}{|c|}{$\begin{array}{c}\text { Unstandardized } \\
\text { Coefficients }\end{array}$} & \multirow{2}{*}{$\begin{array}{c}\begin{array}{c}\text { Standardized } \\
\text { Coefficients }\end{array} \\
\text { Beta }\end{array}$} & \multirow[b]{2}{*}{$\mathrm{t}$} & \multirow[b]{2}{*}{ Sig. } \\
\hline & B & Std. Error & & & \\
\hline (Constant) & .928 & .699 & & 3.139 & .033 \\
\hline Gender & .188 & .135 & .297 & 2.773 & .131 \\
\hline $\begin{array}{c}\text { Education } \\
\text { Level }\end{array}$ & .312 & .096 & .349 & 3.596 & .002 \\
\hline $\begin{array}{c}\text { Income per } \\
\text { month }\end{array}$ & -.039 & .073 & .057 & -.718 & .474 \\
\hline Working place & -.038 & .039 & 076 & .983 & .327 \\
\hline Profession & -0.15 & .039 & 027 & .380 & .705 \\
\hline Media literacy & .178 & .082 & .139 & 4.125 & .025 \\
\hline $\begin{array}{l}\text { Information } \\
\text { supply }\end{array}$ & .304 & .072 & .345 & 4.224 & .000 \\
\hline
\end{tabular}

Demographic variable, media literacy and public information supply variable can predict vocational learning behavior dimension remarkably $(\mathrm{F}=3.139, \mathrm{p}=0.033<0.05)$. Among the variables, education level, media literacy and public information supply all predict the positive vocational learning behavior dimension.

Analysis results testify that new generation rural migrant workers with higher educational level attach more importance 
to media influence on vocational development. New generation rural migrant workers with higher educational level tend to contact social media; they have more powerful ability to conduct daily affairs by the way of social media, and aim to change urban society identification through the media contact process to learn vocational skill. New generation rural migrant workers with higher education level have accumulated rich experience in urban career, it make vocational behavior to adapt with the working place and profession through social media.

\section{CONCLUSION}

The results confirm that there are some differences in social media use of new generation rural migrant workers. Different from most previous studies, this study adopted social layering study method and used layering standards through gender, educational level, income level and working place, profession to demonstrate the social media communication function in new generation migrant workers' continuing vocational learning.

This paper presents some detail analysis of the influence factor on migrant workers social media using in vocational learning field, that involve four aspects: First, new generation migrant workers have greater definite information choice ability, they even acquired vocational learning information or skill through the platform, which has been supervised by government or employment organization, and gradually they have discrimination ability in vocational learning channel and information processing method. Second, the new generation migrant workers have higher education level and media literacy, it makes them to separate themselves from passive social media using phase. They have begun to set up individual life style associated with social media, to meet job-hunting demand and enhance professional skills level, try to reduce the gap compared with urban peer group. Third, with the help of social media using, the new generation migrant workers can attempt to establish career learning relations, this relations not only include workmates learning relationship, but also expand the other career field relationship through social media environment, to satisfy their developing requirement by the way of changing profession. Fourth, new generation migrant workers have cultivated social media using habits; most of them have taken social media as the entertainment and communication method. The ignored vocational learning attribution of social media, for new generation migrant workers, it needs effective guidance from public service and social media information provision.

In brief, although new generation rural migrant workers are highly dependent on social media, they have cultivated their media use choice and habits according to their demands, not just decided by the new media preference. Media communication gratification for these migrant workers is a process, which develops gradually according to the changes in their urban living status. It is a reflection of their demands in the transition from rural to urban culture. The adaptation of new generation migrant workers in urban situation, the core force which push them into better living status, just is the vocational development level. With the increasing pressure of global economy developing and profession competitive, government and organization should help new generation migrant workers to use social media in order to build regular vocational learning system, which will improve them with vocational learning in time.

\section{REFERENCES}

[1] Berger. Asa Arthur, Sociological analysis: Media analysis techniques. Thousand Oaks, CA: Sage, 2011, pp.115-116.

[2] Junhua Huang, Media strategy of new generation migrant socialization. Press Circles, 2011, pp.62-63.

[3] Shenghong Jiang. The problem and strategy research of China new generation migrant rural workers. Lanzhou Academic Journal. 2011, pp.89-92.

[4] Baohua Zhou, The empirical research of new media using and assessment of new generation in Shanghai. Journalism Quarterly. 2011, pp. $145-150$

[5] Wanlin Song, Promotion model research between the mass media on new generation migrant rural workers. News Knowledge. 2011, pp.7-9.

[6] Berger. Asa Arthur, Sociological analysis: Media analysis techniques. Thousand Oaks, CA: Sage, 2011. 